\title{
La participación social en el Sistema Nacional Integrado de Salud Uruguayo
}

Social participation in the Integrated National Health System Uruguayan.

\author{
Fernando Rovira Villademoros \\ Profesor, Universidad de la República. Montevideo, Uruguay.
}

Resumen: El sistema uruguayo de salud, de carácter público/privado, prevé mecanismos de participación social de trabajadores y usuarios en diversos ámbitos del mismo. Dichos mecanismos abarcan tres niveles, que van desde el asesoramiento y la consulta a la gestión directa del prestador público principal y del órgano que administra el fondo que financia el sistema. En la realidad de los hechos, la participación se ve dificultada por diversos factores, algunos propios de la idiosincrasia nacional, y otros compartidos por el resto de los países latinoamericanos que apuestan a la participación social en salud. Examinar esos factores es indispensable para corregir las deficiencias, lo que constituye un desafío para el Estado y la sociedad civil que deben resolverlas conjuntamente.

Palabras Clave: Participación social; trabajadores; usuarios.

Key-words: Social participation; workers.

\section{El derecho a la salud, epicentro del bloque de constitucionalidad de los derechos humanos.}

La consolidación del derecho a la salud como derecho humano fundamental en el régimen jurídico uruguayo es el resultado de la evolución constitucional nacional, por un lado, y del avance vertiginoso del derecho internacional de los derechos humanos a nivel planetario, por el otro.

En efecto, con la incorporación en 1934 de los derechos económicos, sociales y culturales a la Carta Magna, se instaura en Uruguay un Estado Social de Derecho, que, dejando atrás al antiguo Estado Liberal de Derecho, plasma el pasaje de la legalización formal a la constitucionalización sustantiva, "de la soberanía parlamentaria a la soberanía constitucional" (Robaina, 2009, p. 9) y de este modo, la Constitución dejó de ser un mero instrumento de gobierno para transformarse en 
Anais dos III Congresso Iberoamericano de Direito Sanitário / II Congresso Brasileiro de Direito Sanitário

Carta Fundamental humanista y axiológica (Cea Egaña, 2007) cuyo eje central son los Derechos Humanos.

No obstante ello, el derecho a la salud permaneció sin mención expresa en la disposición constitucional que reconoce el derecho de los habitantes de la República a ser protegidos en el goce de su vida, honor, libertad, seguridad, trabajo y propiedad (artículo 7).

Sin embargo, merced a lo que Risso Ferrrand (2008, p. 20 y ss.) describe como el proceso de "aproximación del Derecho Constitucional y el Derecho Internacional de los Derechos Humanos", la Constitución nacional formó parte de aquéllas que a efectos de resolver "tensiones y contradicciones" entre ambos ordenamientos, optaron por "la utilización de disposiciones constitucionales que permitían reconocer rango constitucional a derechos y garantías no mencionados expresamente en el texto constitucional" (Risso Ferrand, 2008, p. 20 y 21). Así, el artículo 72 de la Carta dispone que: "La enumeración de derechos, deberes y garantías hecha por la Constitución, no excluyen los otros que sean inherentes a la personalidad humana o se derivan de la forma republicana de gobierno". Y es a través de este dispositivo, de claro corte iusnaturalista, que el derecho a la salud ingresa a la nómina de derechos humanos fundamentales reconocidos y protegidos constitucionalmente.

Ahora bien, "recientemente, ha comenzado a advertirse, como señala Nogueira, que existe en América Latina (...) una poderosa corriente cada vez más generalizada que reconoce un bloque de derechos integrado por los derechos asegurados explícitamente en el texto constitucional, los derechos contenidos en los instrumentos internacionales de derechos humanos y los derechos implícitos, donde el operador jurídico debe interpretar los derechos buscando preferir aquélla fuente que mejor protege y garantiza los derechos de la persona humana" (Noggueira, Humberto, citado por Risso Ferrand, Martín, 2008).

Uruguay ha incorporado a su ordenamiento interno, tratados de derechos humanos tales como:

La Declaración Universal de los Derechos del Hombre (1948): toda persona tiene derecho a un nivel de vida adecuado que le asegure, junto con su familia, la salud,....la asistencia médica, ....seguros en caso de enfermedad, invalidez etc. (art. 25); 
El Pacto Internacional de Derechos Económicos, Sociales y Culturales (1948): reconocimiento del derecho de toda persona al disfrute del más alto nivel posible de salud física y mental.

La Declaración Americana de los Derechos y Deberes del Hombre (1948);

La Constitución de la OMS: el goce del grado máximo de salud que se pueda lograr es un derecho humano fundamental, sin distinción de raza, religión, ideología, o condición económica o social. "La salud de todos los pueblos es una condición fundamental para lograr la paz y la seguridad"

El Protocolo Adicional a la Convención Americana sobre Derechos Humanos en materia de Derechos Económicos, Sociales y Culturales (San Salvador, 1988): "Toda persona tiene derecho a la salud, entendida como el disfrute del más alto nivel de bienestar físico, mental y social", y son obligaciones de los Estados ratificantes: la atención primaria de la salud, la universalidad de las prestaciones, la inmunización contra enfermedades infecciosas, la prevención de enfermedades endémicas, profesionales y de otra índole, la educación de la población sobre prevención, y la satisfacción de las necesidades sanitarias de los grupos de mas alto riesgo".

En todos estos instrumentos, el derecho a la salud aparece como un derecho humano fundamental, por lo que, bajo la referida teoría del "bloque de constitucionalidad de los derechos humanos", el rango de tal derecho humano fundamental del derecho a la salud resulta incontestable.

Tan incontestable es, que la reforma de la salud iniciada en 2007 tiene como norma matriz la ley de creación del Sistema Nacional Integrado de Salud (SNIS) No. 18.211, de 05/12/2007, cuyo artículo 1ํ․ textualmente establece: "La presente ley reglamenta el derecho a la protección de la salud que tienen todos los habitantes residentes en el país y establece las modalidades para su acceso a servicios integrales de salud. Sus disposiciones son de orden público e interés social".

\section{La reforma de la salud. El sistema nacional integrado de salud.}

Antes de la reforma, el sector salud en Uruguay se caracterizaba por tener una vasta gama de prestadores de servicios de diversa naturaleza jurídica y financiados en formas también diversas, en el que se distinguían básicamente los subsectores público y privado, internamente heterogéneos, y sin relaciones pautadas de complementación, tanto en lo interno de cada uno, como entre ambos. 
El objetivo central de la reforma era y sigue siendo asegurar el acceso universal a servicios integrales de salud, guiados por los principios de equidad, continuidad y oportunidad de las prestaciones, orientación preventiva, integral y humanista, accesibilidad y sustentabilidad de los servicios, calidad integral de la atención, respetando los principios de la bioética y los derechos humanos de los usuarios, financiamiento solidario, y participación social de trabajadores y usuarios.

$Y$ en aras de ese objetivo, la nueva normativa editada en la ley 18.211 de creación del Sistema Nacional Integrado de Salud introdujo cambios sustantivos en el modelo de atención, en el modelo de gestión y en el sistema de financiamiento.

En el modelo de atención, mediante la sustitución del antiguo esquema prestacional/curativo por uno que privilegia la prevención y promoción de la salud, en base a una estrategia de Atención Primaria en Salud con fortalecimiento del primer nivel de atención.

En el modelo de gestión, a través de la articulación de servicios de salud públicos y privados, integrados en red, bajo la dirección de un órgano central - Junta Nacional de Salud, órgano desconcentrado del Ministerios de Salud Pública, integrado por representantes del Estado, de los prestadores, de los usuarios y de los trabajadores - con niveles de atención definidos e interrelacionados, niveles de administración regionales y locales, y que cuentan con órganos asesores y consultivos representativos de trabajadores y usuarios.

En el sistema de gasto y financiamiento, a través de un fondo único (Fondo Nacional de Salud, FONASA), administrado centralmente, basado en la justicia distributiva y en los principios de solidaridad, equidad y sustentabilidad, y conformado con el aporte del Estado, las empresas privadas, los trabajadores, los pasivos y quienes perciben rentas, además de las partidas presupuestales y extrapresupuestales que se le asignan. El pago a los prestadores por los servicios brindados se realiza con cargo al fondo, y en base a la cuota salud como unidad de medida, determinada por el Poder Ejecutivo según el número de afiliados y el cumplimiento de metas asistenciales.

\section{La participación social en el sistema nacional integrado de salud.}

Los nuevos modelos de atención, de financiamiento y de gestión que propugna la reforma - fuertemente interdependientes entre sí - generan espacios de 
participación ciudadana que la nueva legislación se ocupó de formalizar mediante diversas fórmulas institucionales.

La calificación de orden público e interés social que la ley de creación del Sistema realiza respecto de sus propias disposiciones demuestra " un cambio en la concepción de la salud, los factores que intervienen en sus logros y el rol que debe jugar la sociedad para mejorarlos" y "en cuanto al reconocimiento de la influencia de los factores externos a la red de atención, entre los principios rectores del Sistema se fijan la promoción de la salud con énfasis en los factores determinantes del entorno y los estilos de vida de la población y la intersectorialidad de políticas" (Clavell, 2009, p. 119).

Como corolario de estos cambios, la legislación vigente redimensiona el rol de los ciudadanos y la participación de la sociedad en la esfera sanitaria, consagrando como uno de los principios rectores del Sistema, "la participación social de trabajadores y usuarios" (Ley 18.211, art. 3).

"Es característica esencial de toda sociedad abierta el reconocimiento y el amparo de la existencia de cuerpos intermedios, entre los individuos y el Estado, que enriquecen la vida en comunidad, como asimismo, la consagración del derecho de asociación voluntaria, sin más limitaciones que la moral, el orden público y la seguridad del Estado.... Lo anterior, releva la importancia y trascendencia de la libertad individual de las personas. A su vez, relevante es destacar que en este esquema de libertades individuales y derecho de asociación, además del fortalecimiento que debe promover el Estado de la sociedad civil, cabe exigir a los miembros de ésta la adecuada y suficiente responsabilidad para con el país, como también la promoción de la proactividad de los miembros de la sociedad civil, considerados tanto individual como colectivamente. De esta forma, la participación social y ciudadana requiere de un Estado capaz de fomentar el fortalecimiento de la sociedad civil, como fundamento de una sociedad sana y la profundización democrática, pero al mismo tiempo, de un Estado que permita ámbitos de libertad en aquélla" (Recabarren, 2005, p. 1).

\section{Los niveles de la participación.}

Los niveles de participación que la nueva normativa en materia de salud consagró, y que erigen a trabajadores y usuarios en actores principales del nuevo Sistema, abarcan un amplio espectro que va desde la consulta y el 
Anais dos III Congresso Iberoamericano de Direito Sanitário / II Congresso Brasileiro de Direito Sanitário asesoramiento hasta la gestión de los principales órganos del gobierno de la Salud.

Consejos Consultivos y Asesores de los prestadores privados.

La ley 18.211 en su artículo 12 establece que las entidades prestadoras públicas y privadas, para integrar el Sistema, deben contar con órganos asesores y consultivos representativos de sus trabajadores y usuarios.

Dichos Consejos se integran con seis miembros honorarios, que se distribuyen: dos por el prestador, dos por los usuarios y dos por los trabajadores.

Es obligación del prestador, proveer información a estos Consejos respecto de su estado patrimonial, estados contables, número de afiliados, estructura de recursos humanos etc..

Y es de la competencia del Consejo emitir opinión y propuestas sobre estrategias, políticas, programas y acciones a llevar adelante por la institución, evaluar el cumplimiento de los programas de atención integral dispuestos por el Ministerio de Salud en tanto ente rector, velar por la calidad de los servicios, intervenir en las reclamaciones formuladas por usuarios etc..

En suma, si bien se trata de instancias consultivas no vinculantes, las facultades que la ley otorga a estos Consejos, y las obligaciones que impone a las instituciones prestadoras en relación a ellos, confieren a trabajadores y usuarios organizados un interesante margen de acción que, según la organización y fuerza que en cada lugar alcancen, pueden llegar a incidir indirectamente en la gestión de los servicios respectivos.

Comisión de Bioética y Calidad Integral de la Atención de la Salud.

Dicha Comisión, que los representantes de los usuarios integran, fue creada por Decreto del Poder Ejecutivo No. 610/2005, como comisión asesora de la Dirección General de la Salud del Ministerio de Salud Pública, y tiene entre sus competencias la de contribuir al mejoramiento de la calidad de atención a los usuarios, incorporando al concepto de calidad los aspectos éticos y el contenido humano que la atención en salud debe privilegiar. 
La Junta Nacional de Salud (JUNASA).

Como fue dicho, se trata de un nuevo órgano de gobierno del Sistema que administra el Seguro Nacional de Salud (SNS),y que se integra, por un lado, con representantes del Poder Ejecutivo (Ministerios de Salud y de Economía) y Banco de Previsión Social, y por otro lado, con representantes de la sociedad civil: usuarios, trabajadores y prestadores.

A diferencia de las modalidades de participación anteriores, en este caso, el rol que la ley asigna a trabajadores y usuarios es de gestión directa. Y lo es, nada más ni nada menos, que en lo relativo al manejo y control de los dineros del Sistema, dado que es la JUNASA el órgano que administra el Fondo Nacional de Salud. Y como también la JUNASA es quien suscribe con los prestadores los llamados Contratos de Gestión, en los que se establecen las metas que aquellos deben cumplir, el rol de las organizaciones sociales se incrementa, participando de las decisiones en relación a la calidad del Sistema y sus prestaciones.

El Directorio de la Administración de Servicios de Salud del Estado (ASSE).

La segunda ley aprobada en la construcción del Sistema Nacional Integrado de Salud fue la de descentralización de la Administración de Servicios de Salud del Estado (ASSE) (Ley. 18.161, de 27/7/2007, art. 2), prestador público más importante del país que desde hacía setenta años formaba parte de la estructura del Ministerio de Salud como órgano desconcentrado.

"Respecto a los fundamentos esgrimidos por los promotores de la Reforma para la descentralización de ASSE, se señaló como necesario que la administración de las instituciones públicas de asistencia médica quedara fuera del ámbito del Ministerio de Salud Pública, debiendo reservarse para esta Secretaría de Estado la responsabilidad de la regulación y control de la materia sanitaria" (Odriozola, 2009, p. 342).

El Directorio que gobierna al nuevo servicio descentralizado consta de cinco miembros, tres de los cuales son representantes del Poder Ejecutivo, y los otros dos representantes de la sociedad civil: uno, de los trabajadores del organismo, y el otro, de los usuarios del mismo.

La importancia del rol que esta ley asigna a trabajadores y usuarios se potencia, no solo porque la integración al Directorio implica la participación a nivel de 
la gestión directa del organismo, sino por las especiales características que este organismo tiene como prestador público de salud.

"En términos objetivos, ASSE es la mayor empresa pública del país y el prestador de salud de mayor tamaño. Además, por la magnitud de las consecuencias de sus acciones está destinado a marcar el rumbo de la reforma, del cambio de modelo de atención. Transformaciones en su calidad de atención o su gestión, por su tamaño e importancia, implican cambios en el sistema todo, tanto en las políticas propias de los privados como en los vínculos entre privados y el Estado" (Clavell, 2009, p. 128).

\section{Los problemas de la participación. Avances. Desviaciones. Desafíos.}

La consagración jurídica de los mecanismos de participación que se acaban de reseñar, constituye, sin duda alguna, un avance cualitativo en relación a la situación anterior a la reforma del sistema, en cuanto habilita el ingreso de la sociedad civil al gobierno de la salud desde distintas posiciones institucionales.

Múltiples autores desarrollan el elenco de beneficios que la participación social aporta a los sistemas de salud: impacta en "la calidad, equidad y efectividad de los programas de salud", califican al participante y su entorno social como "sujetos más informados, con mayor capacidad de hacer valer sus derechos ante el sistema", corrige la "asimetría de información entre los expertos y los no expertos. Es decir, entre la comunidad científica, las empresas prestadoras de servicios,...los representantes políticos, gestores de los recursos públicos y privados,...y por otro lado, los ciudadanos que no tienen ni la formación médica ni la información que necesitan para tomar decisiones sobre tratamientos, asignación de recursos y reclamos que deben realizar ante lo que consideren incumplimientos o ineficiencias del sistema", "mejora la calidad de las decisiones", "permite integrar a los procesos de toma de decisión distintos elementos de la vida social....entre (los que) se cuentan elementos que afectan el impacto de los tratamientos médicos pero que, a la vez, son afectados por los mismos, como por ejemplo las situaciones familiares, personales y de tipo socioeconómicas o las vinculadas al mundo del trabajo de los usuarios", habilita una "rendición de cuentas horizontal entre distintos actores sociales", etc.. (Clavell, 2009, p. 135 y 136).

Sin embargo, pese al funcionamiento de los mecanismos formales de participación dentro del sistema, y de la promoción de la participación desde la 
Anais dos III Congresso Iberoamericano de Direito Sanitário / II Congresso Brasileiro de Direito Sanitário rectoría del mismo, los datos de la realidad indican que los mencionados beneficios y la consolidación de un modelo sanitario participativo lejos está de alcanzarse, y ello, por múltiples razones:

\section{Asimetrías, contradicciones y ausencias en la participación de los trabajadores.}

Por un lado, y en relación a la participación de los trabajadores en la dirección del Sistema, los avances y desarrollos son asimétricos. Mientras la participación a nivel de la Junta Nacional de Salud muestra resultados favorables, la que se ejerce a nivel de la gestión del prestador público, dominada por una lógica sindical cuestionada desde dentro y desde fuera del Sistema, concibe su nueva ubicación institucional como la conquista de un espacio para reivindicar, y en lo posible, satisfacer sus demandas gremiales, y no como corresponsabilidad en la gestión del organismo, con el compromiso institucional que la misma exige.

A ello se agrega la ausencia del gremio médico en las distintas instancias institucionales de participación. Ello, debido a que su sindicato representativo - de carácter horizontal - está por fuera de las organizaciones sindicales de trabajadores de la salud pública y privada y, consecuentemente, marginado de los ámbitos participativos.

Esa carencia se ve agravada por la existencia de expresiones corporativistas de ciertos colectivos de especialidades médicas - sociedades científicas recientemente erigidas en "sindicatos" - evidenciadas en sus demandas y acciones en relación al Sistema, muchas de las cuales rozan el "abuso de derecho" edictado en el art. 1321 del Código Civil uruguayo y que encajan a la perfección en la descripción que la jurisprudencia nacional realiza al decir que "el abuso de derecho queda configurado: cuando el titular lo ejerce con dolo, o culpa o negligencia; cuando lo usa de manera irrazonable, excesiva o extravagante; o sin necesidad o interés legítimo, o en forma irregular o agraviante; o causa un perjuicio inmotivado; o tiene intención de perjudicar; o se lo ejerce en forma contraria a la moral, las buenas costumbres o de mala fe; o más allá de la necesidad determinada por la necesidad individual; o cuando se los desvía de los fines de la institución o para los que fue conferido; o se los utiliza en forma contraria al Derecho Natural; o de manera que afecte la solidaridad social; o se provoca un daño excesivo en relación a las consecuencias normales a su ejercicio" (Anuario de Derecho Civil Uurugayo, T. T. XXXIV, Montevideo, FCU,2008, p 8). 
Conformación reciente, fraccionamiento y carencia de recursos en la participación de los usuarios.

El colectivo de usuarios del Sistema, si bien está llamado a ser el aliado estratégico del Estado en la reforma de la Salud, es el que mayores dificultades presenta derivadas de su reciente conformación y reconocimiento legal como grupo intermedio.

Es quien debió asumir la nueva identidad que las circunstancias de la época le asignaron.

"De la noción de paciente original, pasivo receptor de políticas y tratamientos, se pasa a la de usuario que adquiere el derecho a elegir y utilizar bienes y servicios de salud, para llegar a la de sujetos de derechos, que se informa, controla y decide" (Clavell, 2009, p. 119).

Es así como el carácter reciente de la conformación de los movimientos de usuarios con una visión macro de salud, es una de las razones que mejor explican las dificultades propias de su accionar, y de ubicarse en el panorama sanitario nacional ocupando el rol que el Estado les asignó por vía legal.

Se trata de colectivos que tienen el estigma de haber sido gestados desde el propio Estado para dar cumplimiento a los requerimientos políticos de la hora: la reforma de la Salud y la participación social en sus ámbitos de gobierno.

De las tres organizaciones existentes, Movimiento Nacional de Usuarios de Salud Pública y Privada, Espacio Participativo de Usuarios de la Salud, y Asociación de Usuarios del Sistema de Salud, sólo éste último tiene una historia que se remonta a principios de la década de los 90 .

Ahora bien, "mientras los dos primeros comparten el enfoque sanitario integral de la actual reforma y la importancia de construir organizaciones sociales que lo enriquezcan", el tercero y más antiguo se limita a "articular acciones individuales" asumiendo un rol de "mediación entre usuarios y prestadores, evitando en la medida de lo posible la resolución de conflictos mediante juicios" (Clavell, 2009, p. 134), sin una decidida adhesión a los principios de la reforma, y en actitud frecuentemente confrontativa con la conducción ministerial y las restantes organizaciones, lo que la ha colocado fuera de las instancias institucionales de participación.

Es precisamente este fraccionamiento el que también conspira contra una eficiente y fructífera participación social de los usuarios del Sistema. 
De hecho, y por decisiones políticas no siempre claramente explicitadas, los espacios institucionales de participación han sido objeto de un "reparto" entre las dos organizaciones creadas a partir de la reforma, con lo cual, cada una de dichas organizaciones, sin conciencia de pertenencia a alguna organización de segundo o tercer grado que las abarque a todas - hasta la fecha, inexistentes - realizan sus actividades y participan en la toma de decisiones conforme a sus propios criterios y a la realidad propia del ámbito cuya gestión comparten, pero sin tener una unívoca visión de la misión de los usuarios, ni compartir con los restantes movimientos una única concepción estratégica.

Finalmente, la falta de recursos para la promoción y desarrollo de estas organizaciones es otro de los factores que obsta a su eficiencia plena.

Si bien existe una asimetría derivada del "reparto" de posiciones a que aludimos (el cargo en el Directorio de ASSE es rentado, mientras el de la Junta Nacional de Salud es honorario), los fondos que desde el Estado, a través del Ministerio de Salud Pública, se destinan a las organizaciones de usuarios para el cumplimiento de su rol son exiguos.

Y más allá de la creatividad de algunos de sus dirigentes y militantes a la hora de pergeñar mecanismos de financiación de actividades de formación y educación de sus cuadros, la falta de tales recursos traba el desarrollo y crecimiento de estos movimientos.

\section{Los desafíos.}

Los problemas descriptos, lejos de ser patrimonio de la realidad uruguaya, constituyen un común denominador para las naciones latinoamericanas que encaran la participación social, con desiguales desniveles de intensidad, pero en el convencimiento de que la Salud de los pueblos se protege y asegura con la participación de todos: Estado y sociedad civil.

Cierto es que particularidades propias del Estado y la sociedad uruguaya determinan también especificidades que se traducen en dificultades propias: el clientelismo político que dominó al Estado uruguayo durante la mayor parte del siglo pasado, y que tuvo en el Ministerio de Salud y demás organismos públicos del sector un instrumento de primera línea; la consiguiente falta de conciencia de clase en muchos de los trabajadores ingresados al sector que dificulta el proceso de sindicalización y el propio accionar sindical; la desaparición o fusión de instituciones 
mutuales en los años anteriores a la reforma, determinadas por una mala gestión de sus recursos, la fuerte centralización administrativa resistente a la actual política descentralizadora del Gobierno, las tercerizaciones, los problemas endémicos de gestión a nivel público, pero también privado, son algunas de esas peculiaridades que hacen a la cuestión actual.

Por su parte, factores como la rica tradición sindical pautada por un movimiento sindical de central única, combativo y negociador a la vez, la importancia del sector académico que ha conjugado históricamente la atención en salud con la formación profesional de médicos y demás integrantes de los equipos de salud en el sector público, y la calificación profesional de muchos de los integrantes de esos equipos, otorgan al escenario de la Salud características propias favorables.

En ese marco, la legislación de avanzada en materia de participación social en salud generada a partir del 2005 se adelantó respecto de las condiciones objetivas imperantes a la fecha de inicio de la reforma y puesta en práctica del nuevo Sistema.

"La incorporación de nuevas voces y actores, se vuelve así, un punto estratégico para la democratización social y la reconstrucción de vínculos para una ciudadanía activa. Desencadenar democratización y participación social es un proceso no lineal ni exento de conflictos y supone asumir una pedagogía democratizadora que coloca a la democratización del poder como eje de esa construcción. La pluralidad de voces e intereses, conforma un escenario en permanente disputa por la definición y redefinición de derechos, pero estas disputas también se dan en torno al reconocimiento y la legitimidad de las voces. Un escenario de múltiples actores tiende a redefinir y cuestionar los espacios de poder de quienes intervienen en la definición de prioridades de la agenda pública” (Villareal, 2005).

En suma, generar el marco jurídico habilitante para la participación social no es más que una cáscara vacía de contenido, si concomitantemente no se transforman "las estructuras institucionales que funcionan hoy" y se reduce "la complejidad institucional para generar mayores niveles de participación e involucramiento". Y "la tensión entre formalidad de representación y capacidad de propuesta sobre las temáticas debería ser asumida en una nueva lógica democrática de participación, gestión y control" (Villareal, 2005).

Ese camino sinuoso es el que recorre el Sistema de Salud uruguayo y los distintos actores que convergen en él. Y la certeza de las correcciones que el sistema 
Anais dos III Congresso Iberoamericano de Direito Sanitário / II Congresso Brasileiro de Direito Sanitário

exige para generar condiciones para la auténtica participación social es responsabilidad de todos.

La reglamentación de esa participación, que el Estado debió efectivizar hace ya tiempo - y no lo ha hecho -, es una oportunidad para el perfeccionamiento del marco jurídico descripto. En especial, en relación a la forma de elección de los representantes que si se opta por el mecanismo electoral a padrón abierto, en relación a los usuarios, seguramente dinamizará la interna de los movimientos determinando un crecimiento cualitativo de los mismos hacia adentro y hacia fuera.

Lo mismo en relación a la participación de los trabajadores: si respetando el principio de la autonomía sindical, se sientan las bases por vía reglamentaria de la forma y alcances de la participación del sector en los distintos niveles del Sistema, y se introduce el componente médico y el de otras profesiones de los equipos de salud en los procesos de elección de los representantes, se habrá avanzado en relación a la situación actual.

Pero la responsabilidad en la superación de los problemas reseñados es compartida entre el Estado y la sociedad civil, que deben encontrar nuevas fórmulas de relacionamiento en las que el Derecho no es más que la herramienta, aunque una herramienta con capacidad movilizadora.

\section{Referencias}

GAMARRA, Jorge y CARNELLI, Santiago (fundadores). Anuario de Derecho Civil Uruguayo, T. XXXIV, c. 1, p.8, Montevideo : Fundación de Cultura Universitaria, 2008.

CEA EGAÑA, José Luis. Legitimación de la democracia por el nuevo constitucionalismo. En: CEA EGAÑA, José Luis y otros. Estudios Jurídicos No. 4. Montevideo : Facultad de Derecho de la Universidad Católica del Uruguay, 2007.

CLAVELL, Elena y otro. La participación social en el Sistema Nacional Integrado de Salud: opciones y debates. Montevideo : Ministerio de Salud Pública, 2009.

ODRIOZOLA, Miguel. EI proceso de reforma del Sistema de Salud. En: ODRIOZOLA, Miguel y otros. Estudios multidisciplinarios sobre Derecho Médico y organizaciones de salud, Montevideo: Ed. La Ley Uruguay, 2009.

NOGUEIRA, Humberto. Los derechos esenciales o humanos contenidos en los Tratados Internacionales y su ubicación en el ordenamiento jurídico nacional: doctrina y jurisprudencia. Ius et Praxis, Derecho de la Región, Universidad de Talca, Facultad de Ciencias Jurídicas y Sociales, Año 9, No. 1, 2003.

RECABARREN, Lorena y AUBRY, Marcel. Informe especial. Participación social y ciudadana, Santiago de Chile: Instituto Libertad. Ideas para Chile, mayo de 2005. 
Anais dos III Congresso Iberoamericano de Direito Sanitário / II Congresso Brasileiro de Direito Sanitário

RISSO FERRAND, Martín. Algunas garantías básicas de los derechos humanos. Montevideo: Fundación de Cultura Universitaria, 2008.

ROBAINA, Andrés. El derecho fundamental a la salud. En: ROBAINA, Andrés y otros. Régimen jurídico de la asistencia a la salud. Montevideo: Ed. FCU, 2009.

VILLAREAL, Nelson. La larga marcha hacia la igualdad social. Aportes comparados en estrategias de políticas sociales (Argentina, Brasil, Chile. Disyuntivas en Uruguay ante un nuevo gobierno). Montevideo : FESUR, 2005. 